\title{
Bra in the New Era: A Study from the Perspective of Feminism
}

\author{
Zihan $\mathrm{Li}^{1, *}$ \\ ${ }^{1}$ Nanjing University of Aeronautics and Astronautics, College of Art, Broadcast Journalism
${ }^{*}$ Corresponding author. Email: zihanli328@yeah.net
}

\begin{abstract}
The type of underwear, known as the 'bra' , is particularly invested with meanings of femininity, sexuality, and pleasure. There is a clear connection between bra and feminism that arouses a lot of attention in academic researches. This paper examines the latest trend of bra and young women's attitudes of buying and wearing bras taken from indepth interviews exploring people's ideology about feminism today. Bra in modern society is no longer a representative of sexual desire or an object that women feel embarrassed to discuss. By contrast, with the development of bras and the new fashion trend like the bra look coming out, female underwear eventually becomes an object on behalf of female rights and an opponent of patriarchal aesthetic. From the results of the interview, Generation $\mathrm{Z}$ is showing an exoteric attitude towards bra. They are demonstrating much more concern to themselves when they are choosing their bra. Health and comfort is a new style of beauty they are pursuing, and all these latest trends on the bra are evidence of the awakening of female self-awareness.
\end{abstract}

Keywords: bra, feminism, male gaze, bra look, in-depth interview

\section{INTRODUCTION}

The bra is a newly designed garment invented by Henry S. Leshe in 1859. Most females who were living before the 20th century are using corsets. But as time goes on, technology has developed stupendously. More and more new types of fabrics are coming out, tons of talented designers started to appear, all these changes brought women variety kinds of choices about underwear. And because of these successful designers' new ideas and the advertising from celebrities and influencers, individuals' thinking and the meanings of bra have changed from the early 16th century to today.

While in the early 16th century, soon after the original form of the bra, the corset, existed in France, it grew in popularity as an undergarment that helped give women the consideration of the perfect figure. After the 18 century, the corset becomes a symbol of female social status. And those who wore corsets are considered as purer, well-mannered, and more pious compared to those loosely-dressed women. Throughout its history, the corset is believed to have functioned as a coercive apparatus through which patriarchal societycontrolled women and exploited their sexuality [1]. For example, in Henry James' The Portrait of a Lady
(1881), Edith Wharton' s The House of Mirth (1905) and The Age of Innocence (1920); Amy Lowells' Patterns (1917) and Margaret Mitchell' s Gone with the Wind (1936), these writers think corseted body existed as a sign of feminine beauty, fragility, and entrapment.

Finally, in the 20 century, the meaning and style of the corset itself are way more transcendent compared to the past attributed to those iconic designers: Vivienne Westwood, Jean Paul Gaultier, Thierry Mugler, and Alexander McQueen. Corsets are still used in their original forms but have been considered as a form of art. For example: in 1990, Madonna wears a corset which is created by French designer Jean Paul Gaultier in her “ Blond Ambition" tour [2]. So as time flies, with the awakening of women' s self-awareness, the fashion trend of bras that women pursue and what they try to express through their underwear garments has changed from time to time.

Intimate apparel shapes and sexualizes female bodies and figures centrally in women' s conformity to particular, historic notions of embodied femininity [3]. After the era of traditional corsets has passed, the styles of underwear have also changed with the different needs of consumers. In the 1990s, the history of bra stepped 
into a new generation - the "second skin" generation. With the innovation of the underwear fabric, women started to emphasize and pay more attention to their comfort, health, and freedom when they are wearing bras. At the same time, the rise of the feminist movement prompted closer scrutiny of the garments as profitable commodities and restrictive gender markers, and many women made their criticisms widely apparent [4]. According to all these signs of progress, including the changes of the bra itself and individuals' ideology about feminism, this research is going to find out what young women think about the recent fashion trend of bras and how feminism can be seen through the changes of the bra. Exploring the attitude towards bra from Generation $\mathrm{Z}$ is a significant and worthy step taken to analyze the future development of feminism.

\section{METHODOLOGY}

This research is focusing on the recent bra trend and the changing of people' $s$ attitudes towards bras. I designed this research using the method of an in-depth interview. An in-depth interview is a qualitative data collection method that allows for the collection of a large amount of information about the behavior, attitude, and perception of the interviewees. During indepth interviews, researchers and participants have the freedom to explore additional points and change the direction of the process when necessary. It is an independent research method that can adopt multiple strategies according to the needs of the research.

This method is a great way to allow the researcher and participants to have a comfortable relationship to generate more in-depth responses regarding sensitive topics. The success of depth interviewing will, in the long run, depend upon having (a) a frame of reference which provides a theoretical bridge between the type of information needed and the techniques to be used in obtaining it; (b) interviewers trained in the skills and sensitivities needed to detect which dimension they are dealing with at a given moment as the interview progresses; and (c) interviewers trained in the skills and techniques applicable to each dimension. Toward this end, a theoretical frame of reference is presented for distinguishing significantly different dimensions of depth [5]. I wanted to find out what do young girls care about when they are choosing their bras, is beauty more important or do they care more about comfort. Also, I am willing to see their attitudes towards the choice of wearing bras or not. These are the questions I mentioned in the interview.

What' s your attitude towards the trend of Bra Look or wear sports bra outside?

What' s your aesthetic preference for a bra?
Will you wear a bra at home? What' $s$ the purpose of wearing a bra from your perspective? Is it necessary for women to wear a bra? Can women abandon their bras?

What brands will you normally choose when you are purchasing a bra? What are your reasons?

Are you familiar with Victoria' s Secret? Have you ever bought a bra from Victoria' s Secret? What' s your impression of this brand?

Which one is more important when you are choosing a bra, beauty or comfort?

Based on my interview below, I got a preliminary result that young women think they have more choices today. So, I conclude it as a trend of the awakening of female self-awareness.

\section{RESULT}

There are 10 interviewees in total. Considering that bra is still a private topic to discuss in China, the participants are mainly my close friends. A large proportion of the participants in this interview are in their 20s, which means this study shows the attitudes of the latest trend of bra appreciated by Generation Z.

Result1: Fashion trend like Bra Look is strongly appreciated by young women of Generation $\mathrm{Z}$.

Every interviewee in this research shows a positive attitude towards the latest fashion trend of the bra. To be more specific, young women think the Bra Look and wear sports bras outside are both new prevalent styles of garments today. They believe these trends show the single aesthetic of female figures is beginning to change. Healthy body shape is becoming a new fashion trend. Most of the interviewees mentioned that this healthy aesthetic helps women reduce social physique anxiety in some perspective. They also said that this latest trend is a sign showing the awakening of female self-awareness.

Result2: Comfort is much more important than beauty.

Every interviewee chooses comfort rather than beauty in the research. Most young ladies prefer simple bras like bralette because it is flimsy and won' $t$ put much pressure on the breast. The sports bra is also a popular choice for its fashion designs and convenience. They prefer to choose the new brands such as Ubras or NEIWAI as their daily underwear due to their high performance-price ratio and comfortable wearing experience. By contrast, they seldom choose to purchase brands like Victoria' s Secret. For example, Belle told me that Victoria' s Secret brought her the impression of being expensive and exquisite. Also, she expressed that in her perspective, Victoria' s Secret is a brand set 
up to meet the male gaze. The original purpose of this brand is to meet the need for a patriarchal aesthetic. She is not the only interviewee to express this opinion. The original purpose of Victoria' s Secret and its single aesthetic standard become the reason that made young women today unsatisfied.

Result3: It' s up to women themselves whether to wear a bra or not.

Most interviewees think the main purpose of wearing a bra is to optimize the body shape and protect privacy. But still, they choose not to wear bras at home due to their self-comfort. And although these interviewees think that wearing a bra or not only depends on personal preference, which means this behavior is not a "must" , all of them choose to wear bras outside. 23-year-old Ruby said in the interview, “ wearing a bra in daily life shows the attitude that I am formal, appropriate, and respectful." But few of our interviewees, who define themselves as feminists, strongly agree that women do not need to wear a bra on any occasion unless they want to do so.

\section{DISCUSSION}

As underwear became outerwear, the position of wearing, materials, and details had changed, and the phenomenon to expose one's body has increased. The fashion trend about bras today is related to female rights and freedom profoundly. Also, it is becoming a representation of the awakening of women' $\mathrm{s}$ selfawareness. The bra is not only a garment that women can talk freely about, it is also a fashion element that has been widely used in clothing design and the influencers , daily outfits posted on their social media platforms. Celebrities such as Britney Spears, Lady Gaga, and Paris Hilton have been spotted wearing Dekkers' bra, which has entered the realm of fashion because it is meant to be seen: underwear as outerwear. Nowadays, both the style of Bra Look and wearing sports bra outside are becoming more and more popular all around the world, and this phenomenon is most evident in the generation born in the 00s. Many young women around 20 years old are following this trend and supporting the rise of feminism. They started to express their opinions on social media, discussing having their rights to choose what clothes to wear and believing others should not judge their wearing.

Bordo' s [6] feminist theorization of the role that the body plays in accommodating and resisting regimes of power draws heavily on the Foucauldian idea of the

'docile body'. She argues that homogenous mass culture images of the female body act as normalizing forces against which women measure and modify themselves [7]. Young girls' preference for a bra can also be seen clearly in the results. Although they still take style and beauty into consideration, their choice of bra is preliminary based on comfort. The complicated lace and other kinds of decorations still exist in the design of the bra, but if they are not comfortable enough, they are not likely to be chosen by some customers. Lots of customers choose a bralette instead of a bra with steel rings inside. This phenomenon could show that young women pursue beauty with the condition of comfort in priority. Moreover, they valued "being themselves" as a priority.

As a typical example of bra brands related to sexy design, Victoria' s Secret is not a very popular brand among young girls due to its high price and brand history. For the people who are not familiar with this brand, the most profound impression they have about this brand is its exquisite design. By contrast, people who are acquainted with its original purpose (designing the type of bra to attract men' $s$ attention) and defining the "perfect body" are part of the reasons why they refuse to choose this brand. Amy-Chinn, D [8], who analyzed the campaigns for Wonderbra and Gossard, had given a conclusion. It is text in the advertisement that is needed to position a brand in such a way that it appeals to women on their terms and in a way that makes it clear to them that the rationale for purchase is not the desire for male approval. In 2014, Victoria's Secret released a flat poster standing with 10 graceful models. The slogan read "THE PERFECT BODY", but it was boycotted by more than 16,000 signatures from all over the UK. A similar rejection can be seen in this research, young girls today do refuse to consume Victoria's Secret partly because of its history. Later in 2018, Victoria's Secret' s chief marketing officer was asked whether he would consider using transgender or plus-size models. He said: "I don' $t$ think it' $s$ necessary. This is a fantasy show, a 42-minute special entertainment." [9] These examples demonstrate the brand concept of Victoria' s Secret is filled with patriarchal values and the male gaze, and that is totally against the feminism trend today.

With the awakening of feminist consciousness, Victoria's Secret has gradually been labeled as “ materialized women" and accused of " a female underwear brand that genetically pleases men”. Its brand concept appears to be incompatible with the current women trend. Victoria's Secret's definition of beauty and sexy is too thin, too stubborn to "perfect body", and it ignores diversified aesthetic trends. People gradually began to be dissatisfied: Why should the definition of "perfect" made by Victoria's Secret become the standard of beauty? However, the new trend of sports bras and comfortable bras provides a more diverse standard of the "perfect body" . Instead of promoting a narrow definition of beauty like what Victoria' s Secret used to do, the newly coming out brands are friendly to women in all types of body 
shapes. In this way, a lot more sizes are made to fit the greater diversity in the definition of beauty.

UBRAS, a start-up brand of bras, is a perfect example of this. In the past centuries, bras used to be a sensitive topic. Individuals were not confident enough to talk about underwear freely, and the most typical meaning most people think the bra could express is related to sexuality (like the corsets which once enjoyed great popularity during the Victorian era). The bra in early history was a symbol of the patriarchal style. But as time flies, the "to make myself look sexier" and " showing I am seductive" are no longer the only words that bras can communicate. Since women are more independent today, they pursue comfort over beauty, and a sexy bra is no longer just a tool to seek attention from men. This new brand decreases body image anxiety because women don' $\mathrm{t}$ need to cater to old aesthetic standards and live in the "male gaze" anymore.

But I am not saying that the sexual function of women' s bras had completely disappeared. There is still a fine line for bra between showing beautiful female bodies dressed in bra to present powerful femininity, and to meet the need of sexual desire. Although in modern society today, a vast majority of women no longer wear a bra to cater to the male gaze, it seems that women wearing bras is still an obligatory demand, they cannot abandon their bra outdoors. But most young women refuse to wear bras when they are at home. In their perspective, wearing bras outdoor is a behavior to protect their body privacy, it is not a necessary behavior, but a choice. And most of the interviewees, believe it' $\mathrm{s}$ personal stuff and think everyone should show respect to other people' $s$ thinking. While some other interviewees, strongly agree that there is no need for women to wear a bra outdoors, as Aronson, Pamela [10] said through his interview, these kinds of women were supportive of equal opportunity, abortion rights, equality in childhood socialization, and "social justice" and were concerned about issues such as sexual assault. This proves that the bias of "must wear bras" is slowly disappearing and our opinions are gradually changing and accepting more diverse ideas which stimulate further development of bra trends.

\section{CONCLUSION}

Looking through the papers which focus on feminism study, the great mass of researchers mentioned the relationship between females, selfawareness and bra but seldom do research studies on the outfit trend of bra to demonstrate feminism through the changes of the bra. For example, Jantzen, C. [11] concluded through her study that bra is consumed to express women' $\mathrm{s}$ social, inter-psychological identity as well as to impress the body - to thrill and arouse it
- thereby enhancing an intra-psychological identity. Although this theory still makes sense today, young women today are showing much more concern for their body comfort. This means compared with the women living in 2006, women' s social, inter-psychological identity can be seen or analyzed through their choices of bra, but no longer needs to be a certain purpose for women buying bras.

Also, from the interview, young women' $\mathrm{s}$ appreciation of the Bra Look and sports bra fashion illustrates that a new function of bra is coming out: a kind of fashion element. The old meaning and position of bras have changed, and with the sports bra getting popular, the sexual meaning of bra slowly begins to disappear especially among young females. Tons of new bra brands holding high the banner of feminism provide new choices for women. By contrast, Victoria' s Secret is rejected by some customers because of its past patriarchal aesthetic and narrow definition of beauty. Although women prefer to choose comfortable bras rather than the ones that only have the function of showing a perfect body shape, this does not mean the sexual function of the bra has been completely abandoned by women. Like I mentioned in the discussion part, for the meanings that the bra can express, there is a fine line between showing body figures when they are dressing a bra to present powerful femininity and meeting the need of sexual desire. This study is based on a small sample of interviews with a relatively homogenous group of young female respondents. More research is needed to investigate the remaining implication of bra and how these old meanings and functions can coexist with the feminist part today.

\section{ACKNOWLEDGMENTS}

First of all, I would like to extend my sincere gratitude to all my interviewees. Without them, without their opinion and attitudes towards bras, I cannot finish this paper. I am also deeply indebted to Professor Nichole for her great teaching of media, culture, and communication, which triggers my interest in this research. Special thanks should go to my friends who have put considerable time and effort to help me to find more interviewees and giving me a lot of support.

\section{REFERENCES}

[1] Steele, Valerie, (2001).The Cultural History of the Corset, NY: Yale UP.

[2] Maria Carolina Zanette \& Daiane Scaraboto (2018): From the corset to Spanx: shapewear as a marketplace icon, Consumption Markets \& Culture, DOI: 10.1080/10253866.2018.1497988 
[3] Fields, J. (2007). Epilogue. Bra vs. Bra: Feminist Intimate Apparel Art. In An Intimate Affair (pp. 272-288). Berkeley: University of California Press. https://doi.org/10.1525/9780520941137-011

[4] Hilary Hinds \& Jackie Stacey (2001) Imaging Feminism, Imaging Femininity: The Bra-Burner, Diana, and the Woman Who Kills, Feminist Media Studies, $\quad 1: 2, \quad 153-177, \quad$ DOI: $10.1080 / 14680770120062114$

[5] Gorden, Raymond L. (1956). Dimensions of the Depth Interview. American Journal of Sociology, 62(2), 158-164. doi:10.1086/221956

[6] Bordo, S., 1993. Unbearable weight: feminism, western culture, and the body. Berkeley: University of California Press.

[7] Rachel Wood (2014): 'You do act differently when you're in it': bra and femininity, Journal of Gender Studies, DOI: 10.1080/09589236.2013.874942

[8] Aronson,Amy-Chinn, D. (2006). This is just for me(n): How the regulation of post-feminist bra advertising perpetuates woman as object. Journal of Consumer Culture, 6(2), 155-175. doi:10.1177/1469540506064742

[9] Brown,G.Shaw. (2014, November 7). Victoria's Secret Changes Controversial "Perfect Body"Slogan.AbcNews.https://abcnews.go.com/Li festyle/victorias-secret-controversial-perfect-bodyslogan/story? $\mathrm{id}=26735138$

[10] Pamela (2003). Feminists Or "Postfeminists"?: Young Women's Attitudes toward Feminism and Gender Relations. Gender \& Society, 17(6), 903922. doi:10.1177/0891243203257145

[11] Jantzen, C. (2006). Becoming a 'woman to the backbone': Bra consumption and the experience of feminine identity. Journal of Consumer Culture, 6(2), 177-202. doi:10.1177/1469540506064743 